\title{
二重球および二重円筒テーラー渦の分子シミュレーション
}

\section{Molecular simulation of Taylor vortices between coaxial spheres or coaxial cylinders}

\author{
○学 神谷 拓（名城大院） 正 宇佐美 勝（名城大）
}

Taku Kamiya, Meijo University, 1-501 Shiogamaguchi, Tempaku-ku, Nagoya 468-8502, Japan

Masaru Usami, Meijo University, 1-501 Shiogamaguchi, Tempaku-ku, Nagoya 468-8502, Japan

\section{1. 緒言}

テーラー渦 ${ }^{(1) \sim(3)}$ の解析は古くから行われている. 本報告 では，内円筒の表面（あるいは内球の赤道面）が音速と同程 度で回転する同心二重円筒（あるいは同心二重球）に生じる テーラー渦を DSMC 法(直接シミュレーションモンテカルロ 法) (4)により再現した。圧縮性のテーラー渦を考えた場合, 密度と回転速度の任意の組み合わせにより，たとえ $\operatorname{Re}$ 数を 一定に固定しても, 渦の発生状況は大きく異なることが考え られる、DSMC 法は, 計算が発散しない, 境界条件を与えや すいなどの特徴があるものの, 従来の衝突計算法では, 渦を 正確に再現するために, 流れ場を平均自由行程より小さなセ ルで分割することが必要条件であった．本報告では，粗いセ ル分割が可能な新衝突計算法 (U-system) ${ }^{(5)}$ を適用して渦の 解析を行った，粗いセルによるDSMC 計算は，今後の三次 元テーラー渦解析を可能にするものとして期待が持てる.

\section{2. 新衝突計算法 (U-system)}

本計算法は, 衝突計算直前に一方の分子 $\mathrm{P}$ を，あたかも， もう一方の分子 Q の位置に移動させたかのように分子速度 の補正を行う。今, 流れ場中の分子は, すべてある温度と流 れ速度を持つ局所平衡状態の速度分布関数(Maxwell 分布)に 従うものと仮定する. 分子 $\mathrm{P}$ の位置の分布関数を $\mathrm{f}_{1}$, 分子 $\mathrm{Q}$ の位置の分布関数を $\mathrm{f}_{2}$ とし, 分子 $P$ の速度が $\mathrm{f}_{1}$ 上の一点 $A$ にあるものとしよう. 衝突計算に際して,このA 点を分布関 数 $\mathrm{f}_{2}$ 上のどこかに移せばよいことになるが, 最も自然な方法 は, $\mathrm{f}_{1}$ 上の $\mathrm{A}$ 点の位置と $\mathrm{f}_{2}$ 上の位置が相対的に同じになるよ う移動させることである(B 点).この $\mathrm{B}$ 点位置を求める計算 は簡単で, $\mathrm{x}$ 方向速度成分 $\mathrm{u}$ について考えると, 式（1）で 計算できる。

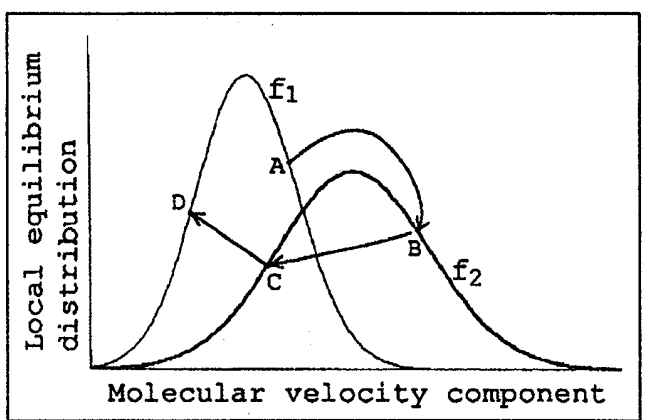

Fig. 1 Modification of velocity in the new intermolecular collision scheme

$$
u_{2}=U_{2}+\left(u_{1}-U_{1}\right) \sqrt{T_{x 2} / T_{x 1}}
$$

ここで, $\mathrm{T}_{\mathrm{X} 1}, \mathrm{~T}_{\mathrm{X} 2}$ および $\mathrm{U}_{1}, \mathrm{U}_{2}$ は, 分子 $\mathrm{P}, \mathrm{Q}$ が位置する 2 点の $\mathrm{x}$ 方向温度および流速の $\mathrm{x}$ 成分である. 分子間衝突の計 算は，この修正された分子速度 $u_{2}$ を用いて行い，得られた 衝突後の分子速度 $u_{2}^{*}$ (C 点) は, 分子 $\mathrm{P}$ を元の位置に戻す操 作のために，式（2）を用いて再び修正される (D 点).

$$
u_{1}^{*}=U_{1}+\left(u_{2}^{*}-U_{2}\right) \sqrt{T_{x 1} / T_{x 2}}
$$

\section{3. 計算条件}

\begin{tabular}{|l|l|l|}
\hline 解析対象 & 二重円筒 & 二重球 \\
\hline 対象気体 & $\mathrm{Ar}$ & $\mathrm{Ar}$ \\
\hline 内円筒(球)半径 $[\mathrm{m}]$ & 0.1 & 0.1 \\
\hline 外円筒(球)半径 $[\mathrm{m}]$ & 0.125 & 0.114 \\
\hline 高さ $[\mathrm{m}]$ & 0.1 & - \\
\hline アスペクト比 & 4 & - \\
\hline 温度 $[\mathrm{K}]$ & 288 & 288 \\
\hline クヌッセン数の逆数 & 2500 & 1600 \\
\hline 圧カ(Pa) & 500 & 573.3 \\
\hline レイノルズ数 & 3598 & 2188 \\
\hline 水平(半径)方向セル数 & 375 & 204 \\
\hline 鉛直(周囲)方向セル数 & 1500 & 4420 \\
\hline セル数合計 & 56.25 万 & 90.2 万 \\
\hline 分子数 & 150 万 & 160 万 \\
\hline 内円筒 $($ 球)回転速度 $[\mathrm{m} / \mathrm{s}]$ & 346.3 & 346.3 \\
\hline マッハ数 & 1.414 & 1.414 \\
\hline
\end{tabular}

\section{4. 結果}

Fig.2, Fig.3 は同心二重球テーラー渦について, 従来法に よる計算と新衝突法によるものを，同じセル分割で比較した 結果である（新衝突法では，極付近を含めた全体図も描いて ある). 赤道を中心として上下に渦が発生し, 球の上下に大 きな循環流が発生する。そしてこれが最も支配的な流れとな る. 新衝突法の方で, 従来法よりも小さな渦が発生している.

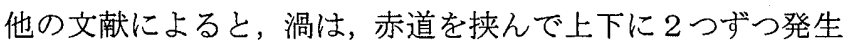
するのが自然ではあるが，今回の解析では 確認することが できなかった。理由は以下のことが考えられる。

・強い循環流の影響により渦が縮められ，渦の数が減少

・赤道付近の遠心力の大きさは 場所による変化量が小さい ため 赤道直上で必ずしも外向きの流れが生じない

・圧縮性の何らかの影響

なお，内球回転速度を上げた場合，渦の大きさが小さくなる ことを確認した.これは, 内球速度を上げたことにより循環 流が強くなり，渦の大きさが小さくなったものと考えられる。

Fig.4, Fig.5 はそれぞれ従来法, 新衝突法における二重円 筒解析における結果である. 新衝突法に関しては, 渦ができ る途中の過程も Fig.5(a)として描いてある. まず壁面近傍に 小さな渦が複数発生し, それらが吸収, 合体を繰り返して渦 が徐々に成長し，定常状態となる，定常状態の図を比較する と, 渦の数と強さに違いが見て取れる. なお渦の数は, 用い る乱数によっても変化する。新衝突法で, 従来法よりも強い 渦が発生している. 新衝突法ではセルを見かけ上細かくした と同じ効果が得られるので, 本来あるべき速度変化を忠実に 再現できたものと考える.

\section{5、時間経過によるトルクの変化}

Fig.6 は，従来法による二重球解析において，内球および 外球の表面で発生するトルクの時間変化を示したもので,

Fig.7は, 新衝突法によるトルク曲線である. 従来の衝突法 
で定常状態に達したときのトルク值を Tqs とし，両図の縦軸 はこれで無次元化している。横軸は 1 ステップ時間 $\left(=7.02 \times 10^{-8} \mathrm{sec}\right)$ の 800 倍を単位にとった時間である. Tqi は 内側の球で発生するトルク, Tqo は外側の球で発生するトル クである. Tqi は最初大きな值を示している.これは最初静 止していた状態から球を突然回転させたために発生したも のである，そしてそこから一気に減少していく，一方， Tqo は外球が静止しているためゼロからスタートし，時間が経過 して分子の動きの影響が伝わってくると, 徐々に值が増加し ていく，そして次第に Tqi と Tqo が近づき，その後は共に大 きな変化はせず定常状態となる.トルクが定常状態になると, テーラー渦が発生していることをはっきりと確認できる. 新 衝突法では, 従来法の約 1.1 倍の強さで定常状態に達してい る.しかし，別の計算において，伝達されるトルクにもっと 大きな差が現れた場合があるので，これについては，今後プ ログラムの検討等を含めて調査する必要がある.

一方，二重円筒のトルク曲線では，上下端を拡散反射条件 にすると，内・外の円筒表面におけるトルクが一致しなかっ た. 円筒の上下端をトルク算定の対象としなかったことが原 因であると思われる。

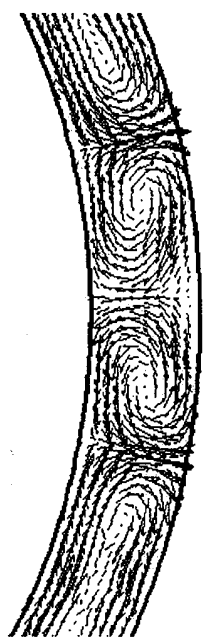

Fig. 2 Conventional collision scheme

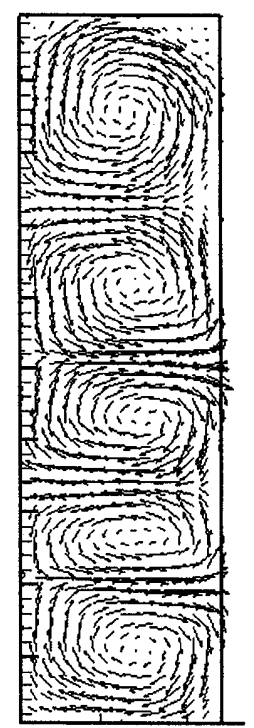

Fig.4 Conventional collision scheme
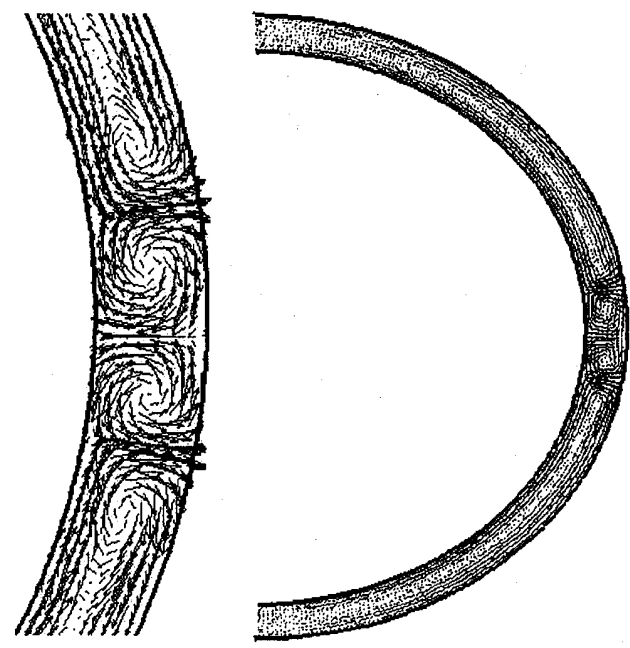

Fig.3 New collision scheme

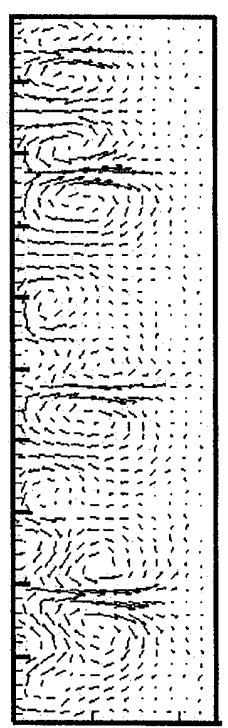

(a)

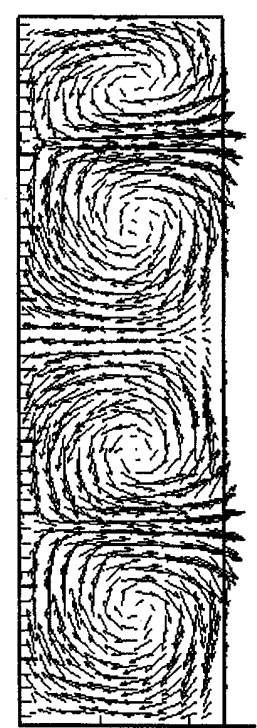

(b)
Fig. 5 New collision scheme

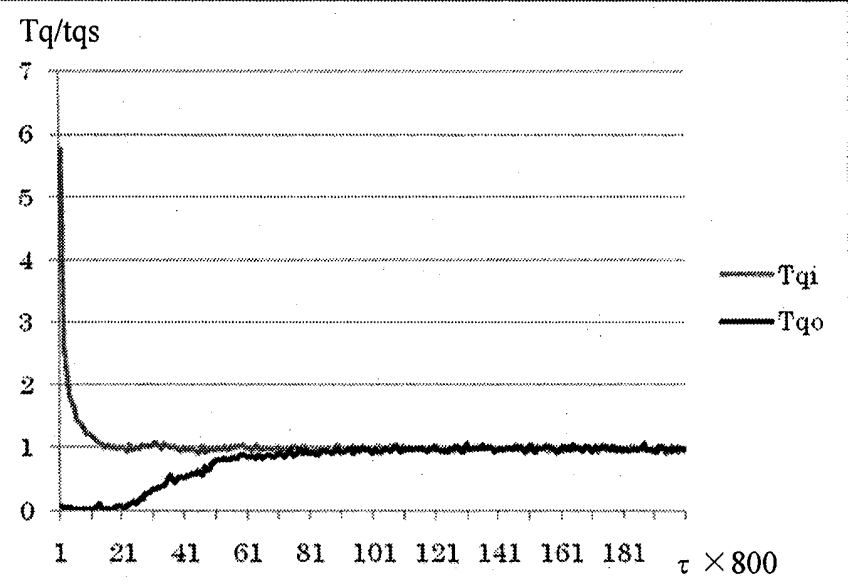

Fig.6 Torque curve (conventional collision scheme)

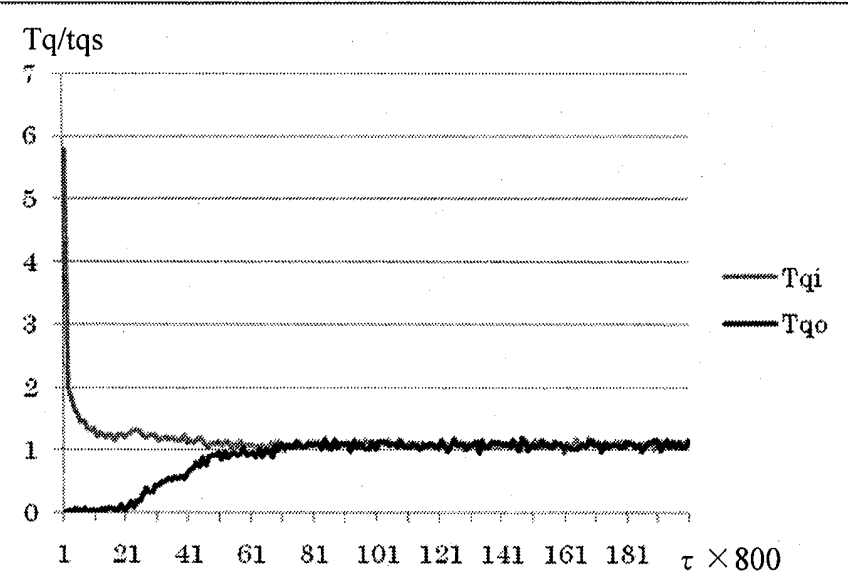

Fig.7 Torque curve (new collision scheme)

\section{6. 結論}

（1）新衝突法を用いることにより，従来法より強い渦の発生 が確認できた。

(2) 二重球解析において，今回の解析ではレイノルズ数を変 化させても渦の数に変化は見られなかった.これについて は，今後さらなる検討が必要である。

(3) 内球速度を速くすると, 循環流の影響により渦の大きさ が小さくなる。

(4) 二重円筒解析において，内側円筒を超音速で回転させた 場合，渦の数に変化が見られたが，用いる乱数により影響 を受けるので，衝突法の違いによる効果を結論づけるには 至っていない.

（5）円筒の上下端を拡散反射条件にした場合，トルク計算に は上下端も考慮する必要があり，内・外の円筒面だけでは 発生するトルクは一致しない。

\section{参考文献}

(1) Riechelmann, D., Nanbu,K., Monte Carlo Direct Simulation of Taylor Instability in Rarefied Gas, Physics of Fluids A, 5-11 (1993), 2585-2587

(2) Wimmer M. Experiments on a viscous fluid flow between concentric rotating spheres. J. Fluid Mech, 1976, 78-2: 317-335 (3) Buhler K. Symmetric and asymmetric Taylor vortex flow in spherical gaps. Acta Mechanica, 1990, 81: 3-38

(4) Bird, G. A., Molecular Gas Dynamics and the Direct Simulation of Gas Flows, (1994), Clarendon.

(5) 宇佐美, 衝突計算を改良した DSMC 法の圧縮性流体への 適用，ながれ，26-4 (2007), 273-282. 